\title{
The role of food allergy in the etiology of infantile eosinophilic pustular folliculitis
}

\author{
Zuhal Metin ${ }^{1}$ and Mustafa Metin ${ }^{2}$ \\ ${ }^{1}$ Zonguldak Ataturk State Hospital \\ ${ }^{2}$ Zonguldak Bulent Ecevit Universitesi Tip Fakultesi
}

September 25, 2021

\begin{abstract}
Eosinophilic pustular folliculitis (EPF) of infancy (EPFI), as a rare variant of EPF, is an inflammatory dermatosis characterized by recurrent outbreaks, itchy papulopustules and involvement of scalp and other body areas. In our case, we present a 3-monthold boy with persistent itchy vesiculopustular rashes on the scalp, hands and feet, eosinophilia in the peripheral blood test, widespread eosinophil clusters in the swab of the pustule and egg allergy in the skin prick test. This is the first case of EPFI associated with food allergy that is permanently suppressed by elimination diet with the limited use of cetirizine.
\end{abstract}

The role of food allergy in the etiology of infantile eosinophilic pustular folliculitis

Metin Zuhal MD', Metin Mustafa MD $^{2}$

${ }^{1}$ Department of Dermatology, Zonguldak Ataturk State Hospital, Zonguldak, Turkey

${ }^{2}$ Department of Family Medicine, Bulent Ecevit University School of Medicine, Zonguldak, Turkey

RUNNING TITLE: Food allergy and folliculitis CORRESPONDENCE

Metin Zuhal, MD, Department of Dermatology, Zonguldak Ataturk State Hospital, Site / Zonguldak, Turkey Email:dr.zuhalmetin@gmail.com

WORD, FIGURE AND TABLE COUNT

Word: 1069 Figure: 1 Table: 1

Hosted file

1 PAI Main Text.docx available at https://authorea.com/users/436042/articles/538650-the-roleof-food-allergy-in-the-etiology-of-infantile-eosinophilic-pustular-folliculitis 


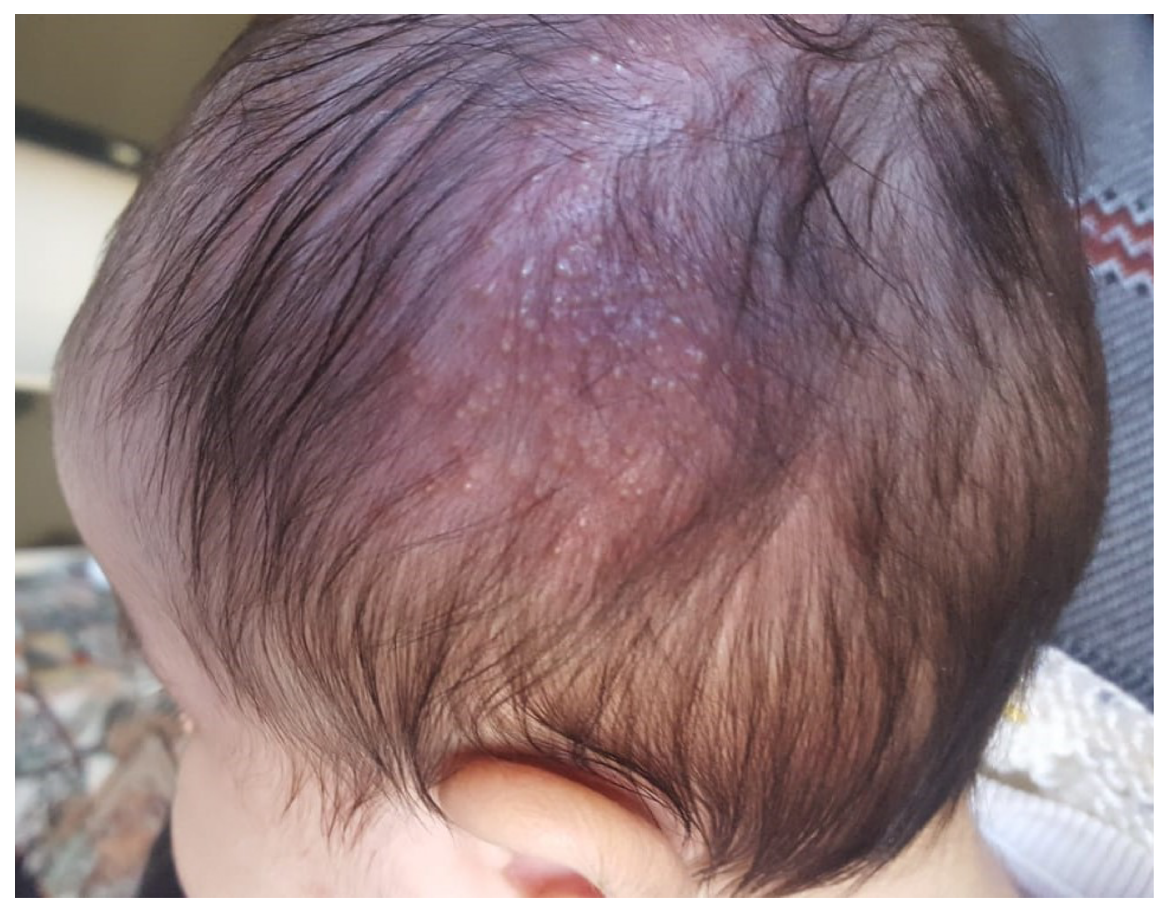

